\title{
Cognitive-Behaviorism and Experientialism in Emergency Medicine Training: From Theory to Practice in a Teaching Hospital
}

\author{
Taiwo Akhigbe $^{1^{*}}$ \\ ${ }^{1}$ Department of Emergency Medicine, Altnagelvin Hospital, Northern Ireland, UK
}

Corresponding Author: Taiwo Akhigbe, MBBS, MCh, MSc, PgD, FRSPH, Department of Emergency Medicine, Altnagelvin Hospital, Northern Ireland, UK. Tel: +44-7459712427, Email: akhigbetaiwo@yahoo.com

Received May 30, 2018; Accepted July 25, 2018; Online Published September 30, 2018

\begin{abstract}
Learning theories can be important in developing result-producing and sound teaching methods if not viewed as merely academic concepts in emergency medicine education. Several learning theories have been encountered and utilized in our emergency department (ED). Most times, learning can be self-directed, self-motivated, lifelong learning. However, the drawbacks of applying learning theories in our ED are that the teaching is not well-structured or systematic, the environment can be very challenging on busy days, and effective learning under such conditions can be limited. Despite the busy and tension-soaked environment in an ED, learning is still very possible for motivated trainees who understand the dynamics of learning and teaching theories. Understanding disease demands that trainees be knowledgeable, skillful, and capable of self-directed, lifelong learning.

Keywords: Learning, Teaching Methods, Emergency Medicine

Citation: Akhigbe T. Cognitive-behaviorism and experientialism in emergency medicine training: from theory to practice in a teaching hospital. Int J Med Rev. 2018;5(3):87-89. doi:10.29252/JJMR-050301.
\end{abstract}

\section{Introduction}

Emergency medicine is a specialty that deals with medical and surgical emergencies of diverse forms and arrays. Teaching junior trainee doctors in emergency medicine involves education and training to become a competent emergency medicine physician who can practice safely as a consultant over the long term. Stenhouse ${ }^{1}$ maintained that there are four fundamental mechanisms of education (medical education inclusive), namely training (skill acquisition), instruction (information acquisition), initiation (familiarization and socialization in social norms and values), and induction (critical thinking and problem solving). On these four pillars rests the concept of teaching and learning in our emergency department (ED). Playdon and Goodsman ${ }^{2}$ described training as a learning process with known outcomes, often dealing in repetitive skills and uniform performances which are expressed as standards or criteria. Based on this approach to education and training, strategies for learning and teaching are broad-based because of the extensive knowledge and skills to learn, including the following:

1. Patient consultation as a learning opportunity in emergency rooms;

2. Teaching and learning through active observation;

3. Teaching and learning at the bedside;

4. Teaching and learning by facilitated reflection;
5. Teaching and learning through small group lectures and clinical tutorials.

The current paper gives a synopsis and analysis of learning theories, teaching methods, and skills used in my current practice in emergency medicine, from theory to practice, from a detailed front-seat observer and participant.

\section{Summary of Learning Theories as Practiced in the Emergency Department}

Learning theories can be important for developing resultproducing and sound teaching methods if not viewed as merely academic concept in emergency medicine education. Learning theories encountered and utilized in our ED are highlighted in Table 1. Two prominent learning theories in practice are experientialism (Kolb) and cognitive-behaviorism (Bandura).

\section{Kolb's Experiential Learning Theory}

Emergency medicine is a very busy specialty with multifarious case presentations requiring doctors to process a huge amount of data in a short time in order to make treatment plans for multiple patients. Kolb's theory is used in teaching junior doctors and is described by David Kolb ${ }^{3}$ as "the process whereby knowledge is created through the transformation of experience." This theory entails learning by doing (experiential) and

Copyright (C) 2018 The Author(s). This is an open-access article distributed under the terms of the Creative Commons Attribution License (http:// creativecommons.org/licenses/by/4.0), which permits unrestricted use, distribution, and reproduction in any medium, provided the original work is properly cited. 
Table 1. Summary of Learning Theories in Emergency Medicine

\begin{tabular}{|c|c|c|}
\hline Learning Theory & Cognitive-Behaviorism & Experientialism \\
\hline Brief description & $\begin{array}{l}\text { Acquisition of cognitive description from role modelling, behavioral } \\
\text { rehearsal, and observed behavior to assume new roles. }\end{array}$ & $\begin{array}{l}\text { The learner reflects on previous experiences and further } \\
\text { application of this learning to new encounters. }\end{array}$ \\
\hline Main concepts & $\begin{array}{l}\text { Learning results from the interaction with and the observation of others } \\
\text { in a social context. }\end{array}$ & $\begin{array}{l}\text { Learning is the process whereby knowledge is created } \\
\text { through the transformation of experience. }\end{array}$ \\
\hline Related theories & Bandura's Social Learning Theory & Kolb's Experiential Learning Theory \\
\hline Key proponent & Bandura (1986) & Kolb (1984) \\
\hline
\end{tabular}

learning by observation with facilitated reflection on such experience encountered to improve subsequent performance.

Kolb further elaborates on experiential theory mechanism through a cycle of learning (Figure 1) within the following stages: concrete experience, reflective observation, abstract conceptualization, and active experimentation. Effective learning occurs when a learner progresses through these four stages.

Kolb recognizes that a learner also has a natural preference for the point at which s/he tends to enter the cycle, based on their genetic makeup and past experiences. ${ }^{5}$ These preferred learning styles are termed accommodating, diverging, assimilating, and converging (Figure 1). Prior learning is imperative in the development of current clinical knowledge or clinical skills.

Kolb's experiential learning is a key feature in our ED and includes clinical tutorials for junior and middle-grade doctors (observed weekly) that are presented in a problembased manner and involve specific clinical conditions, skills, or concepts important to emergency medicine. It was applied on a one-to-one basis by presenting a patient to a consultant for further instruction and teaching of skills or knowledge followed by valuable feedback and subsequently updating of portfolios. The consultant's role as an educator is described by Kolb and $\mathrm{Kolb}^{6}$ as the facilitator, being warm and affirming to promote initiative and being authoritative and reflective themselves to aid the reflective exercises.

One of the major benefits of Kolb's theory is that students can see themselves progress and, as a result, develop reflective practice habits. ${ }^{3}$ Reflection is a skill taught and assessed in

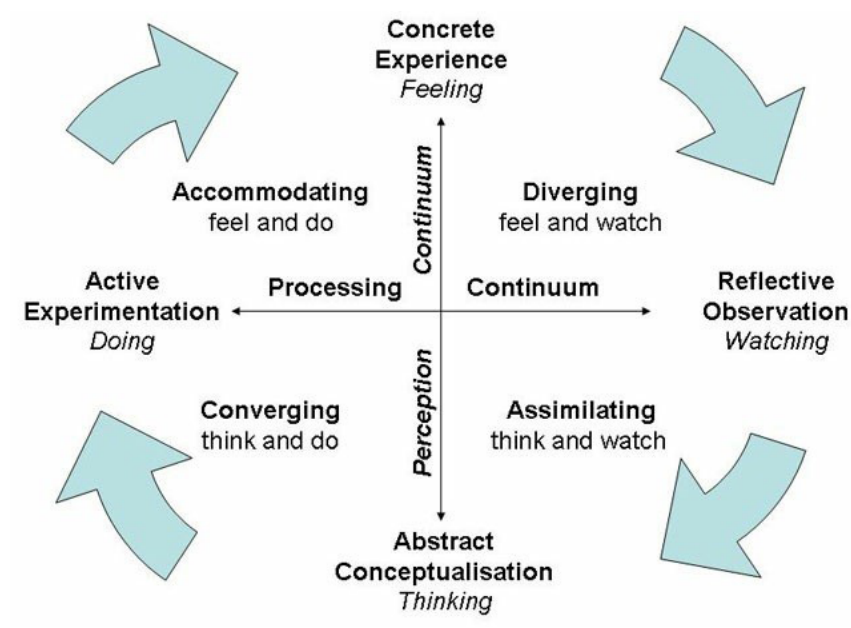

Figure 1. Kolb's Learning Styles and Cycle. ${ }^{4}$ emergency medicine, irrespective of the work shift. Focus is important with constant monitoring and rethinking of cases encountered, mistakes made, and omissions observed for effective and efficient reflection. As part of our workplace assessment, written reflection in e-portfolio form is a requirement for the successful and satisfactory completion of training. Reflection is a life-long skill in medical practice.

\section{Bandura's Social Learning Theory}

Behaviorist theories of classical and operant conditioning are the hallmark of Albert Bandura's social learning theory, ${ }^{7}$ which describes how stimuli trigger responses through mediating processes. This theory further shows that learning occurs as a result of interaction with others and the environment. Bandura acknowledged that cognitive processes were important for observational learning to occur. ${ }^{8}$ Hence, this theory has been labelled a bridge between behaviorist and cognitive learning theories. The four steps in observational learning are attention, retention, reproduction, and motivation. Motivation is a catalyst for superior achievement following sterling performance in case-based discussion or mini-clinical examination which can be sustained by positive remarks and good encouragement following intelligent completion of an assigned clinical task.

Bandura's theory suggests that one learns from observing his environment, and most human behaviors are learned through modelling by keen, deliberate, focused, and consistent observation. In emergency medicine, junior doctors initially observe the consultant (trainer) in all steps from history taking, to physical examination, to management, including how to perform clinical skills and procedures. The consultant demonstrates good clinical practice, confidence, enthusiasm, and a positive attitude toward patient and learner. Morris and Neve ${ }^{9}$ acknowledged that observing positive role models helps shape the development of a learner's professionalism. An emergency room is a learning environment that has positive and negative clinical scenarios which can be recognized as models for learning through keen observation which can modify knowledge and the development of clinical skills.

A consultant's role as a teacher is to provide and optimize a learning environment for junior doctors that is conducive to maintaining attention, focus, and keen observation of the teacher as a role model in order to develop clinical skills and expertise. In addition, learning from role models like a consultant is common place in EDs; it is a widely used method of education in clinical rotation. ${ }^{10}$ Fortunately, I have had numerous encounters with charismatic consultant 
role models with great attributes as described by Wright and Carrese ${ }^{11}$ as having sound clinical knowledge/skills and a patient-centered approach with displays of empathy and compassion.

In this model, the teacher is majorly in control. Great teachers will more likely produce great physicians, especially in areas involving clinical and psychomotor skills. Hence, a teacher can be described as a live model, a verbal instructional model, or a symbolic model, depending on the impact made in the life of the trainee.

Cognitive load theory, as an off-shoot of cognitivebehaviorism, is applicable in our emergency medicine training. It involves the use of memory following intermittent rehearsal of stored information regarding the patient seen before the final presentation of the summary during handover. Improving the four observational skills (attention, retention, reproduction, and motivation) is very relevant to effective and efficient handoffs. However, with many patients encountered, synthesizing a huge amount of data in a short time to present these patients can be very challenging.

\section{Conclusions}

Despite the busy and tension-soaked environment of the ED, teaching and learning are still very possible by motivated trainees who understand the dynamics of learning and teaching theory and that understanding disease demands knowledgeable and skillful trainees capable of self-directed, lifelong learning. ${ }^{12}$ The outcome of applying these theories in our Emergency Department (ED) are (1) the teachings is not well-structured or systematic; (2) the consultants are well-motivated to teach and guide junior trainees; (3) the environment can be very challenging on busy days, and effective teaching and learning in such an atmosphere can be limited; and (4) learning is majorly self-directed and self- motivated by observation and reflection.

\section{Conflict of Interest Disclosures}

The author declares that there is no conflict of interest.

\section{References}

1. Stenhouse L. An introduction to curriculum research and development. London: Heinemann; 1975:52-83

2. Playdon ZJ, Goodsman D. Education or training: medicine's learning agenda. BMJ. 1997;314(7085):983-984. doi:10.1136/ bmj.314.7085.983a.

3. Kolb DA. Experiential learning: experience as the source of learning and development. Englewood Cliffs, NJ: Prentice-Hall; 1984.

4. 12. Mcleod S. Kolb- Learning Styles 2017. Available at: https:// www.simplypsychology.org/simplypsychology.org-Kolb-LearningStyles.pdf. Accessed October 13, 2018.

5. Kolb A, Kolb DA. Kolb's Learning Styles. In: Seel NM, ed. Encyclopedia of the Sciences of Learning. Boston, MA: Springer US; 2012.

6. Kolb A, Kolb DA. Experiential learning theory as a guide for experiential educators in higher education. ELTHE: A Journal for Engaged Educators. 2017;1(1):7-44.

7. Bandura A. Social learning theory. Englewood Cliffs, NJ: PrenticeHall; 1997.

8. Bandura A. Social foundations of thought and action: A social cognitive theory. Englewood Cliffs, NJ: Prentice-Hall; 1986.

9. Morris R, Neve H. Teaching and Learning Professionalism. In: Cantillon P, Wood DF, Yardley S, eds. ABC of Learning and Teaching in Medicine. 3rd ed. London: Wiley-Blackwell; 2018:9196.

10. Irby DM. Clinical teaching and the clinical teacher. J Med Educ. 1986;61(9 Pt 2):35-45. doi:10.1097/00001888-19860900000005.

11. Wright SM, Carrese JA. Excellence in role modelling: insight and perspectives from the pros. CMAJ. 2002;167(6):638-643.

12. Dornan T. Osler, Flexner, apprenticeship and 'the new medical education'. J R Soc Med. 2005;98(3):91-95. doi:10.1258/ jrsm.98.3.91 